\title{
DIE GESKIEDENIS VAN DIE DEPARTEMENTE GRIEKS EN LATYN AAN DIE UNIVERSITEIT VAN DIE VRYSTAAT
}

\author{
L Cilliers \& A Snyman (Universiteit van die Vrystaat)
}

'n Era is verby, 'n era waartydens die twee antieke tale wat aan die basis van ons Westerse beskawing lê, wat van die eerste vakke was wat aan die Universiteit van die Vrystaat (destyds die Grey Universiteitskollege) aangebied is, nou op die agtergrond geskuif word. Die twee tale, Grieks en Latyn, het ontwikkel tot twee sterk departemente in die Fakulteit Lettere en Wysbegeerte (later Geesteswetenskappe), maar in die laaste dekade eers hul selfstandigheid verloor, en daarna verloor een van die twee, Latyn, sy bestaansreg aan die UV. In die hieropvolgende verslag word die geskiedenis van die Departemente Grieks en Latyn sedert hul ontstaan in 1904 nagevolg, en hul rol in die universiteit en die land uitgelig.

Trefwoorde: Antieke tale; Departement Grieks aan die UV; Departement Latyn aan die UV; rasionalisasie aan die UV.

\section{Departement Klassieke Tale}

In 1904 het die Grey Universiteitskollege (die voorloper van die latere Universiteit van die (Oranje) Vrystaat) tot stand gekom en is die eerste BA-kursus ingestel. Die eerste rektor was dr Johannes Brill (1904-1907), 'n gebore Hollander afkomstig van die stad Utrecht, wat in Klassieke Lettere gepromoveer het, en dan ook die eerste dosent in Klassieke Tale was. Hy was 'n verfynde, minsame en beskeie mens en het tot die einde as 'ou Doktor' bekend gestaan.

Van 1908 tot 1913 was die Departement Klassieke Tale in die hande van prof George Robertson, (MA Edin, BA Oxon). Hy word opgevolg deur prof William Conlin (MA Dublin), wat blykbaar hoofsaaklik vir Latyn verantwoordelik was. Hy was ook verantwoordelik vir die instelling van die Conlinmedalje (dit het later 'n boekprys geword) vir die beste derdejaarstudent in Latyn. 'n Voormalige rektor, prof B Kok, het nog mooi herinneringe aan hierdie eentonige, maar bekwame en gewaardeerde leermeester wat van 1914 tot 1926 die leerstoel aan hierdie inrigting beklee het. Hierna vind ons 'n verdeling van die departement in Grieks en Latyn, wat elk selfstandige departemente geword het.

\section{Departement Grieks}

In die Departement Grieks vind ons vanaf 1926 tot 1949 die welbekende prof John Ross (MA Univ Kaapstad, DLitt honoris causa UNISA 1947) aan die hoof nadat 
hy reeds vanaf 1912 tot 1925 lektor in Grieks was. Prof Ross se oupa was 'n wewer naby Aberdeen in Skotland; sy vader was een van die Skotte wat na SuidAfrika gekom het om die NG kerk te dien; hy word in 1863 predikant van Lady Grey in die Kaapprovinsie. John Alexander Ross is op 17 Februarie 1885 te Lady Grey gebore. Hy ontvang sy opleiding tot sy eerste jaar BA van sy pa, en daarna te Stellenbosch en Kaapstad, en word 'n uitblinker wat, soos 'n kollega al gesê het, nie volle erkenning ontvang het nie. 'n Oud-student van hom, prof CA Van Rooy, onthou hom soos volg: 'Prof Ross was een van die voortreflikste dosente van die Klassieke in Suid-Afrika, en het sy lewe gewy aan sy vak en sy studente, by wie hy een van die mees beminde onder die professore was. Hy was groot in sy nederigheid. Afgesien daarvan dat hy meester van Grieks en Latyn was, was hy perfek tweetalig (Afrikaans en Engels), en het hy ook 'n hele aantal moderne tale geken, onder andere Frans, Duits, Italiaans en Russies (lg. het hy op ouderdom 53 begin studeer)'. ${ }^{1}$ Onder sy publikasies is daar die bekende Euripides, digter en denker, met 'n vertaling van sy Hippolytus (Swets \& Zeitlinger, 1940) en talle vertalings van Griekse werke, en onder sy ongepubliseerde werke verskeie vertalings van Russiese werke oor die Klassieke.

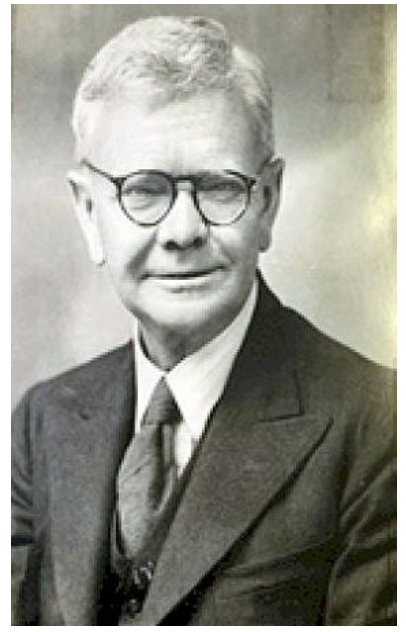

Prof John Ross

(Departementele besit)

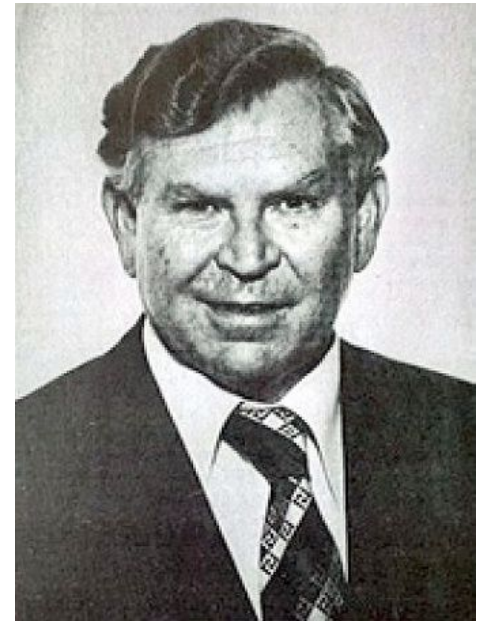

Prof CA Van Rooy

(Departementele besit)

In 'n persoonlike brief aan L Cilliers in die negentigerjare. 
Prof Ross is opgevolg deur prof CA Van Rooy (MA UOVS, MA Oxon, DLitt UOVS). Charles (Charl) Van Rooy het sy studies aan die Universiteit van die Vrystaat voortgesit in Oxford as Rhodes-beurshouer, en het daarna teruggekeer as lektor (1949-1950), senior lektor (1951-1956) en professor (1957-1965) aan die Universiteit van die Oranje Vrystaat voordat hy aan UNISA afgestaan is. Sy uitgebreide proefskrif is in 1965 by Brill gepubliseer onder die titel Studies in Classical satire and related literary theory en het die standaardwerk oor klassieke satire geword. Sy veelsydigheid blyk uit publikasies op vele ander gebiede, soos onder andere 'n Afrikaanse teksboek vir voor- en nagraadse studente oor antieke Griekse geskiedenis, ${ }^{2}$ en 'n studie van die Griekse archaïse digters saam met JH Barkhuizen en WJ Henderson wat deur Teubner uitgegee is. ${ }^{3}$ Gunstige resensies toon dat hy ook op hierdie gebied internasionaal bekend was. Hy was 'n stigterslid van die internasionale tydskrif Acta Classica en van die Klassieke Vereniging van Suid Afrika. Hy was 'n navorser by uitnemendheid, en was dikwels oorsee vir navorsing en later as gashoogleraar.

Prof Van Rooy is in 1966 opgevolg deur prof JP (Jannie) Louw (MA, DLitt UP), nadat hy vanaf 1955-1961 lektor was, senior lektor van 1962-1965 en professor van 1966-1972. In 1961 sit hy sy taalstudies in Utrecht voort en 'n dosyn of wat taalkundige publikasies verskyn daarna. Hy was ook lid van die SA Linguïste Vereniging en van die Nuwe Testamentiese Werkgemeenskap. Op albei se kongresse was hy 'n gereelde bydraer; hy word ook betrek by die hersiene Afrikaanse Bybelvertaling. Hy was 'n baanbreker op die gebied van diskoersanalise en leksikografie. Prof Louw het in 1992 'n eredoktorsgraad van die Universiteit van die Vrystaat ontvang - 'n tweede, hy het in 1990 reeds 'n eredoktorsgraad van die Universiteit van Potchefstroom ontvang.

In die oorgangsperiode tussen die vertrek van prof Jannie Louw in 1972 en die koms van prof Andries Snyman in 1974 het prof Kotie Grové as departementhoof opgetree (1972-1973); daarna is hy na die Universiteit van Port Elizabeth as departementshoof. In 1973 het Kobus Cronjé by hom aangesluit as senior lektor. Dit was 'n onsekere jaar vir die departement omdat prof Jannie se voorwaarde vir die aanstelling by die Universiteit van Pretoria was dat Jan Barkhuizen, 'n kollega in die departement en bekend vir sy werk op die Griekse liriese poësie, saam met hom moes kom.

In 1974 het prof Andries Snyman by Kobus Cronjé, wat reeds in die departement was, aangesluit as hoof van die departement Grieks tot en met 1986.

2 Antieke Griekse geskiedenis van die steentydperk tot die eeu van Perikles, Butterworth, 1980.

3 Kalliope. Band 1. Griekse jambiese en elegiese poësie van Archilochos tot Theognis. Unisa, Pretoria 1986; Kalliope. Band 2. 'n Bloemlesing van Griekse liriese poësie van Alkman tot Pindaros. Unisa, Pretoria, 1988. 
In 1987 het hy dekaan van die Fakuteit Lettere en Wysbegeerte geword waarna prof Kobus Cronjé departementshoof geword het. In 1975 het Louis le Roux by die departement aangesluit en in 1979 Fanie Riekert, wat as navorser die Departemente Grieks, Latyn en Semitiese Tale moes bedien; hy het in 1986 by die Departement Bybelkunde aangesluit.

Die departement het deur die jare probeer om sy deel te doen op die gebiede van onderrig, navorsing en gemeenskapsdiens. Sedert 1974 tot 1986 het die departement 2242 ingeskrewe Griekse studente gehad. Die bloeitydperk van die departement wat studentegetalle betref was in die laat sewentigerjare toe die eerstejaars in die omgewing van 100 was. Meeste van die oudstudente het uiteindelik predikante geword wat reg oor die land in gemeentes diens verrig. 'n Aantal het selfs dosente geword.

Deur die jare het Andries Snyman sy DLitt verwerf (1974), Kobus Cronjé sy MA (1976), en sy DLitt in 1984, en Louis le Roux sy DLitt in 1986. Fanie Riekert het in 1984 sy Doktorsgraad in Ou Testament verwerf en in 1996 sy MA in Grieks. Sommige lede van die departement was by 'n paar inter-universitêre projekte betrokke, soos die projek oor Diskoersanalise wat op verskeie publikasies uitgeloop het, die projek oor Nuwe Testamentiese Stilistiek wat uiteindelik uitgeloop het op die publikasie Style and discourse in 1983, en die Grammatikaprojek wat uitgeloop het op die publikasie van Grieks met begrip. 'n Inleidende grammatika toegespits op die Griekse Nuwe Testament, Werkgroep vir Griekse Onderrig, 1995.

Die een breë veld van navorsing waaraan al die departementslede in 'n mindere of meerdere mate deel gehad het, is die kombinasie van stilistiek en semantiek, alhoewel ander velde soos vertaalkunde en rekenaargesteunde onderrig ook aandag geniet het.

Twee hoogtepunte van 1974-1987 is:

1) Die publikasie van Kobus Cronjé se proefskrif Dionysius of Halicarnassus, De Demosthene: A critical appraisal of the status quaestionis, followed by a glossary of technical terms (Spudasmata 39, Hildesheim \& Zürich 1986). Sy promotor was prof HLF Drijepondt van Latyn.

2) Die publikasie van Style and discourse, with special reference to the text of the Greek New Testament (United Bible Societies, 1983), waaraan proff EA Nida, JP Louw, AH Snyman en JV Cronjé meegewerk het. Volgens die United Bible Society is 102,718 kopieë daarvan verkoop vir die vertaling van die Bybel in 600 tale oor die wêreld heen. 


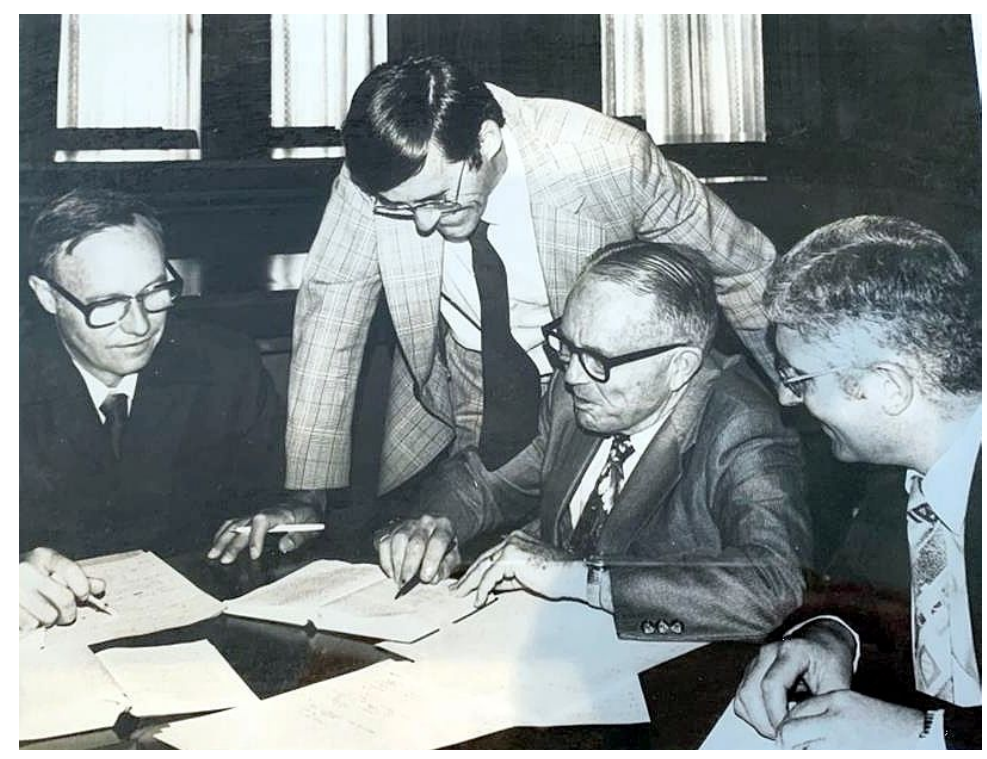

Proff JP Louw, J Van W Cronjé, EA Nida en AH Snyman by een van die samesprekings oor Style and discourse, Januarie 1982.

Uit laasgenoemde blyk die noue samewerking tussen die departement en die Bybelgenootskap. Die departement was betrokke by verskeie vertalings- en ander projekte en hul navorsingspublikasies (ongeveer 60 tussen 1974 en 1986) het gefokus op stilistiek, semantiek en die retoriek van die Nuwe Testamentiese Grieks. Prof Snyman was ook voorsitter van die Bybelgenootskap van SA se nasionale raad vir twee termyne (1998-2001 en 2001-2005), en het meegewerk aan die Nuwe Afrikaanse Bybelvertaling in 2014.

Ter wille van besparing is die hele universiteit in 1997 onderwerp aan 'n rasionalisasieproses. Tydens hierdie proses is 25 persone wat reeds 55 jaar oud was, gevra om te bedank; dit was egter nie genoeg nie, en in 1998 moes nog 5 gaan. Onder hierdie omstandighede het die dekaan besluit om nie na die Department Grieks terug te keer nie, en het prof Cronjé ook besluit om te bedank, dus was daar net net een persoon oor in die departement (dr LV le Roux). Die rasionalisasieproses was 'n eenvoudige syfer-oefening, wat berus het op die dosent-student verhouding in elke departement en die personeel se ouderdom. Gevolglik is die 'swak' Griekse departement ingelyf by die 'sterk' Kommunikasiekunde departement, en die 'swak' Departement Latyn by die 'sterk' Engelse een. Die kriterium van algemene voortreflikheid - wat as basis van evaluering by enige universiteit behoort te dien — is nie deur die universiteit in ag 
geneem nie. Dit is dus logies dat veral die kleiner (taal)departemente waar dikwels uitstekende werk oor 'n lang periode gedoen is, die prys moes betaal.

Beide Grieks en Latyn het na die rasionalisasie finaal hul selfstandigheid verloor (Vir die verdere geskiedenis van Grieks, vide infra.).

\section{Departement Latyn}

In die Departement Latyn is die bogenoemde prof Conlin deur prof Maitland Raynes (MA Oxon, DPhil Berlyn), opgevolg; sy verblyf was egter kortstondig, naamlik van 1927 tot April 1929. In sy tyd word die bekende en gerespekteerde mnr SJH Steven (MA UCT, BA Oxon, LLB UOVS) as lektor in Latyn aangestel (1927/1928). Later (1929-1940) word hy senior lektor en van 1941-1963 was hy professor in hierdie departement waarop hy 'n onuitwisbare stempel afgedruk het. Talle oudstudente en kollegas onthou hierdie fynbeskaafde mens en bekwame vakman met die warmste toegeneëntheid. 'n Oud-kollega skryf van hom: 'Die skielike heengaan van Steven op 60-jarige ouderdom is 'n geweldige verlies. Hy was ... ook oortuig dat 'n waardering van die Klassieke tradisie as grondslag vir ons kultuur in Suid-Afrika nodig is. Altyd blymoedig, het hy hom nooit gespaar in diens van die universiteit nie ... Beide Ross en Steven het as dosente harder gewerk as enige universiteitsprofessor wat ek ken' ${ }^{4}$ Van prof Steven se briljante studierekord skryf prof Van Rooy: 'He was educated at Paarl Gymnasium, where he won numerous prizes in die first class ... at the age of fifteen. After gaining the BA and MA degrees at the University of Cape Town in 1920 and 1921, both in the first class, he was elected to a Queen Victoria Scholarship and proceeded to New College, Oxford, where he read Greats and took his degree in 1924'. Later behaal hy ook die LLB-graad aan die UOVS, en is as advokaat in die Bloemfonteinse Hooggeregshof toegelaat, maar het nie as advokaat gepraktiseer nie; hy was egter lank vir die doseer van Romeinse Reg verantwoordelik. Hy was ook lank waarnemende dekaan van die Regsfakulteit. Sy veelsydigheid was goed bekend. Hy was onder andere ook president van die UOVS se krieket- en rugbyklubs. Samevattend laat ons prof. Van Rooy weer aan die woord oor hierdie oudleermeester en -kollega: 'Throughout his career he was actively engaged in research, though the many calls upon his time left him little time for publication. While he was, first and last, a superb teacher of the Latin language and literature, his expert judgment in educational matters was much in demand ... To his colleagues and students alike, SJM Steven was one of the most beloved of the university professors ... His shrewdness of judgment was widely respected. His

Opmerking in notas van WJ Richards.

In 'n brief van CA Van Rooy aan L Cilliers waarin hy inligting begin bymekaarmaak vir die geskiedenis van die departemente (ongedateerd). 
intolerance of slackness and an occasional abruptness of manner went with an essentially kindly disposition and a keen sense of humour'. ${ }^{6}$ Prof Jannie Louw vertel van 'n geleentheid toe hy prof. Steven vra waarom hy slegs ses uit tien vir 'n byna foutlose vertaling vanuit Afrikaans na Latyn gekry het, en Steven se antwoord was: 'Louw, you are not writing like Cicero'?

Van 1955-1959 was mnr WJ Richards lektor in prof Steven se departement; in 1960 aanvaar hy 'n senior lektoraat aan die Universiteit van Pretoria om later na die UOVS terug te keer. In 1963-1964 volg die kortstondige verblyf van een van prof Steven se knapste studente, prof HJ Erasmus, MA (UOVS), DLitt et Phil (Leiden), wat daarna as eerste professor van Klassieke Tale na Port Elizabeth vertrek. 'n Lektor wat in hierdie dae die konstante faktor was en gewaardeerde werk verrig het, was mnr. WJ Henderson, MA (US). Sy vertrek as senior lektor na Natal in 1967 was 'n gevoelige verlies.

In die Departement Latyn neem prof Van Rooy in 1965 tydelik waar. Daarna keer prof WJ (Willem) Richards (BCom PU vir CHO, MA, DLitt Utrecht en DLitt UP), terug van Nederland nadat hy in Utrecht gepromoveer het, en word hoof van die Departement Latyn (1966-1978). In 1978 word hy dekaan en kort daarna vise-rektor tot 1986 . Hy het 'n wye belangstelling gehad in o.a. antieke godsdiens, antieke filosofie en historiese grammatika, maar het 'n besonder voorliefde vir die Klassieke gehad. Hy was 'n innemende persoon en met sy breë verwysingsraamwerk het studente by hom veel meer as Latyn geleer. Tyd het nie vir Willem Richards bestaan nie, lesings kon ver oor die tyd aanhou, en dit was nie ongewoon dat 'n student om tienuur in

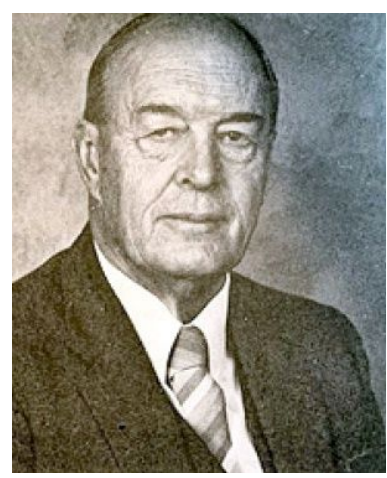

Prof WJ Richards

(uit familiebesit) die aand, ná 'n vergadering met kollegas, ontbied word vir 'n lesing nie. As kultuurmens was hy by talle instansies in verskillende hoedanighede betrokke, onder andere by die Oude Meester Stigting en die SA Bybelgenootskap, wat hom baie na aan die hart gelê het. Hy het ook sy plek volgestaan in liggame wat te doen het met buitelandse verhoudings (veral Nederland en Duitsland), die onderwys, kuns en bewaring.

Prof Willem Richards word in die UV se Feesalbum, Van sink tot sandsteen tot graniet. Die eerste honderd jaar van die Universiteit van die Vrystaat (Universiteit van die Vrystaat, Bloemfontein, 2006) beskryf as 'n man wat

Ibid.

Ondateerbare anekdote. 
daagliks inhoud en gestalte gegee het aan begrippe soos hoflikheid, beskeidenheid, onkreukbaarheid, en bo alles Christenwees'.

Dr JT Benade was senior lektor in die departement van prof. Richards voordat hy na Unisa vertrek het as professor. Van hom sal ons altyd sy prosavertaling van Vergilius se Aeneïs onthou. ${ }^{8}$

Prof Richards is opgevolg deur prof HLF Drijepondt (1978-1984) wat in België gebore is en na 'n paar jaar by UNISA na die UV gekom het as hoogleraar. Prof Drijepondt was 'n tipiese outydse klassikus met 'n grondige kennis van Grieks en Latyn, en was 'n spesialis op die gebied van die Griekse en Latynse retoriek. Sy proefskrif, Die antike Theorie der Varietas, is in 1979 deur Spudasmata in Hildesheim uitgegee.

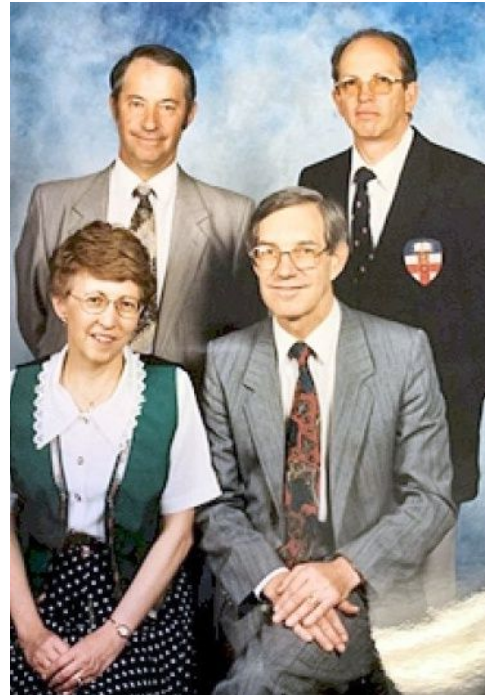

Die Departement Latyn voor ontbinding in 1997. Vlnr agter: Dr Dirk Coetzee, mnr Louis Van Ryneveld; voor: prof Louise Cilliers, dr Johan Cilliers.

In die Departement Latyn was daar vanaf die laat sewentigerjare vier jong dosente, 'n hegte, hardwerkende span wat vir die volgende sowat 20 jaar die departement deur dik en dun sou dra: die egpaar Cilliers wat van die ou RAU gekom het nadat hulle hul doktoraaleksamens in Klassieke Lettere in Leiden afgelê het: drs (later dr) JFG (Johan) Cilliers (MA RAU), Drr Litt et Phil Leiden, DLitt RAU), as senior lektor, en dra (later prof) Louise Cilliers (MA UP, Drr Litt et Phil Leiden, DLitt RAU) wat besig was om kinders groot te maak, op 'n tydelike basis. In die departement was daar ook reeds mnr LF (Louis) Van Ryneveld, (BSc UOVS, MA UOVS, MA University College, London), en mnr (later dr) DJ (Dirk) Coetzee (MA en DLitt UOVS).

$\mathrm{Na}$ die aftrede van prof Drijepondt is Louise Cilliers as professor en departementshoof aangestel (1985). Bedenkinge oor 'n vrou as departementshoof is gou die nek ingeslaan, en die laat tagtigerjare en vroeë negentigerjare was akademies 'n vrugbare tyd. Met die verbod op oorsese akademiese besoeke wat gelig is, het die departement verskeie oorsese hoogleraars as gaste ontvang wat

Vergilius. Die Aeneïs. Universiteit van Suid-Afrika. Pretoria. 1975. 
later ook deur ander Griekse en Latynse departemente in die land oorgeneem is waar hulle lesings gegee het, o.a prof Henk Versnel (Universiteit Leiden), prof Karl Galinsky (Universiteit van Texas in Austen), prof Stephen Harrison (Universiteit Oxford), prof Elizabeth Craik (Universiteit St Andrews), prof A Boyle (Universiteit van Southern California), prof John Scarborough (Universiteit Wisconsin) en prof Sir Ronald Syme (Regius Professor in Antieke Geskiedenis aan die Universiteit Oxford) wat dit so geniet het dat hy die volgende jaar weer gekom het!

Van die vroeë tagtigerjare af totdat skole later nie meer Latyn as matriekvak aangebied het nie, was daar eenmaal 'n jaar 'n Latyndag gereël vir skoliere in die Vrystaat wat Latyn geneem het, waartydens die kulturele agtergrond van die Romeinse beskawing deur middel van kort lesings en films toegelig is, en blokraaisel - en ander kompetisies gehou is om te probeer wys dat die studie van Latyn ook pret kan wees. Daar was ook Latynaande wat deur die dekaan en ander hooggeplaastes bygewoon is, en Romeinse feeste met 'n entoesiastiese senior studentekorps. In 2007 het die Departement Latyn 'n internasionale kongres van die Klassieke Vereniging van Suid-Afrika in Bloemfontein gereel, wat deur van die top oorsese akademici op die gebied van Antieke Geneeskunde bygewoon is. Die referate wat toe aangebied was, is daarna in 'n bundel opgeneem, Asklepios. Studies on Ancient Medicine (Acta Classica Supplement II), met Louise Cilliers as redakteur. In 1992 is lang jare se harde werk bekroon toe die Suid-Afrikaanse Akademie se prys vir vertaling aan proff EL de Kock en L Cilliers toegeken is, ${ }^{9}$ en in dié tyd is prof. Louise Cilliers ook verkies as voorsitter van die Klassieke Vereniging van Suid-Afrika vir twee termyne (1993-1994 en 1995-1996).

Intussen het die onweerswolke egter begin saampak toe Latyn Spesiaal en Latyn I in 1994 deur die Appélhof afgeskaf is as vereiste vir LLB Dit het rampspoedige gevolge ingehou vir die studentegetalle in die departement. Daarmee saam was daar in 1997 'n ewe rampspoedige rondte rasionalisasie dwarsdeur die universiteit waartydens (veral manlike) dosente op 55-jarige ouderdom pakkette aangebied is wat hulle 'vrywillig' moes neem (sien ook bo by Grieks). Dit het veral die Fakulteit Lettere en Wysbegeerte sleg geraak, en spesifiek die Departemente Grieks (sien bo) en Latyn. Drr Cilliers en Coetzee en mnr Van Ryneveld was onder die slagoffers. Die departement se bestaan het aan 'n draadjie gehang; daar is geargumenteer dat 'n departement met net een permanente dosent nie kan voortbestaan nie, en dat geen opleiding verder as Latyn I aangebied sal word nie. Drr Cilliers en Coetzee is toe op 'n kontrakbasis aangestel, en prof Roy Muller van die Departement Engels het Latyn onder sy vleuel geneem en dit het die Deptartement Engels en Klassieke Tale geword. Die voormalige Latiniste het

9 Aristotoles. Poëtika. Vertaling en uitleg van betekenis. Perskor, Johannesburg. 1991. 
toe benewens Latyn ook lesings in die Departement Engels gegee, en dr Cilliers het Semantiek in die Fakulteit Teologie aangebied. Ten einde die verskraalde departement verder te help, het prof Cilliers in samewerking met die Regsfakulteit 'n nuwe kursus, Regstaal en Kultuur ontwerp wat studente 'n breë regsagtergrond gegee het met ook die basiese Latynse terme wat hulle in die regsberoep sou teekom; dit was 'n goeie skuif en het van die begin af studente gelok want dit het hulle onderskei van die gewone massa aansoekers as klerke by prokureursfirmas.

Die ou Departement Latyn het egter teen alle verwagtinge in onder die leierskap van prof. Cilliers en danksy die 'goedkoop' arbeid van drr Cilliers en Coetzee as tydelike dosente, bly voortbestaan as die Departement Engels en Klassieke Tale en selfs gespeen geraak van die Departement Engels in 2009 en die Departement Klassieke Tale geword. Na die samesmelting met Hebreeus in 2010 onder druk van die dekaan ('n ongelukkige huwelik vol frustrasie) het dit die Departement Klassieke en Nabye Oosterse Studie geword; 'n ('gelukkige') egskeiding het gevolg en vanaf 2013 word dit die Departement Grieks, Latyn en Klassieke Studie.

In hierdie tyd het die universiteit baie klem begin lê op navorsing, wat as byna net so belangrik beskou is as studentegetalle. Prof Cilliers het hierdie strooihalm aangegryp en in 1998 in samewerking met die oud-rektor, prof François Retief, antieke mediese geskiedenis begin ontgin, 'n projek wat in die daaropvolgende byna 20 jaar ongeveer 70 artikels in geakkrediteerde tydskrifte gelewer het. In 2005 is die SA Akademie se prys vir interdissiplinêre samewerking aan hulle toegeken. ${ }^{10}$ Van 2005 tot 2009 was prof Cilliers ook redakteur van Acta Classica, en in 2019 verskyn haar boek, Roman North Africa. Environment, society and medical contribution, die vrug van baie jare se navorsing, by Amsterdam University Press in Nederland.

In 2009 neem prof JC Zietsman (BA Regte UP, MA UP, DLitt UP) by prof Cilliers oor en word mede-professor en departementshoof van die Departement Klassieke Tale. Prof Zietsman het hom veral beywer vir die regstudente; benewens sy belangstelling in die geskiedenis en ontwikkeling van die reg, het hy saam met kollegas 'n waardevolle werkboek oor regsterme, sekere regsbeginsels, hofprosedure ensovoorts vir die studente saamgestel. ${ }^{11}$ Van Junie 2010 toe die departement met Nabye Oosterse Studie moes saamsmelt en die Departement Klassieke en Nabye Oosterse Studie geword het, het baie tyd en energie gegaan in die hantering van die spanning tussen die Grieke en Latiniste aan

10 Soos weerspieel in hul boek Health and healing. Disease and death in the GraecoRoman world, Acta Theologica Suppl. 7, Universiteit van die Vrystaat, 2005.

11 Latine legamus et loquamur. Xerox, Universiteit van die Vrystaat, 2017 ('n Engelse uitgawe in 2018). 
die een kant en die Semiete van die ou Departement Semitiese Tale en MiddeOosterse Studie aan die ander kant. Uiteindelik het hierdie departement in Oktober 2013 ontbondel tot afsonderlik die Departement Hebreeus en die Departement Grieks, Latyn en Klassieke Studie.

Saam met prof Zietsman het me Anneli Machin (MEd, UV) in 2009 in die departement begin; sy was vanaf die begin verantwoordelik vir die Griekse studente in die Fakulteit Teologie en Religie. Met die aftrede van prof Zietsman in 2017 word sy waarnemende departementshoof. Met die vooruitsig dat Latyn en Regstaal en Kultuur van 2020 nie meer as keusevakke in die Regsfakulteit aangebied sal word nie, maar slegs met spesiale goedkeuring as ekstra vak wat nie in die Regskurrikulum val nie, verskuif die klem in die departement nou na Klassieke Studie. Grieks word egter steeds deur die departement aangebied.

Die gevolge van die wegval van Latyn en Regstaal en Kultuur as vakke is 'n verlies in die leerplan van die Regstudente; die mate van kennis van Latyn wat hulle opgedoen het, sou hulle wel nie in staat gestel het om regstekste sommer so te lees nie, maar hulle sou wel intelligente afleidings kon maak om die betrokke passasie te verstaan. Die aanleer van die tegniek om te vertaal, help ook logiese denke, wat so nodig is vir regspraktisyns. Maar belangriker as dit — die aanleer van Latyn impliseer veel meer as net die taal: dit behels 'n hele kultuur wat aan die basis van ons Westerse beskawing lê. In Regstaal en Kultuur veral het die klem op agtergrondskennis en tydsomstandighede gelê wat studente die ontstaan van die groot regsbronne soos die Corpus Iuris Civilis sou laat verstaan. Al hierdie kennis en vaardighede word studente nou ontneem, terwyl 'n mens graag sou wou sien dat toekomstige regters 'n breë agtergrondkennis het.

Oswald Spengler se teorie van die opkoms en ondergang van 'n beskawing is in die kleine ook op hierdie departement van toepassing: vir ietwat meer as 'n eeu is Grieks en Latyn aan die Universiteit van die Vrystaat aangebied, het hoogtepunte beleef, maar as gevolg van omstandighede in die 21 ste eeu sneuwel Latyn - die tragiese einde van die aanbieding van 'n taal aan die Universiteit van die Vrystaat, 'n taal wat vir soveel eeue een van die boustene van die Westerse beskawing was.

\section{BRONNELYS}

Machin, A. Mondelinge kommentaar.

Richards, W J. Ongepubliseerde aantekeninge.

Snyman, A H. Ongepubliseerde aantekening.

Zietsman, J C. Mondelinge kommentaar. 